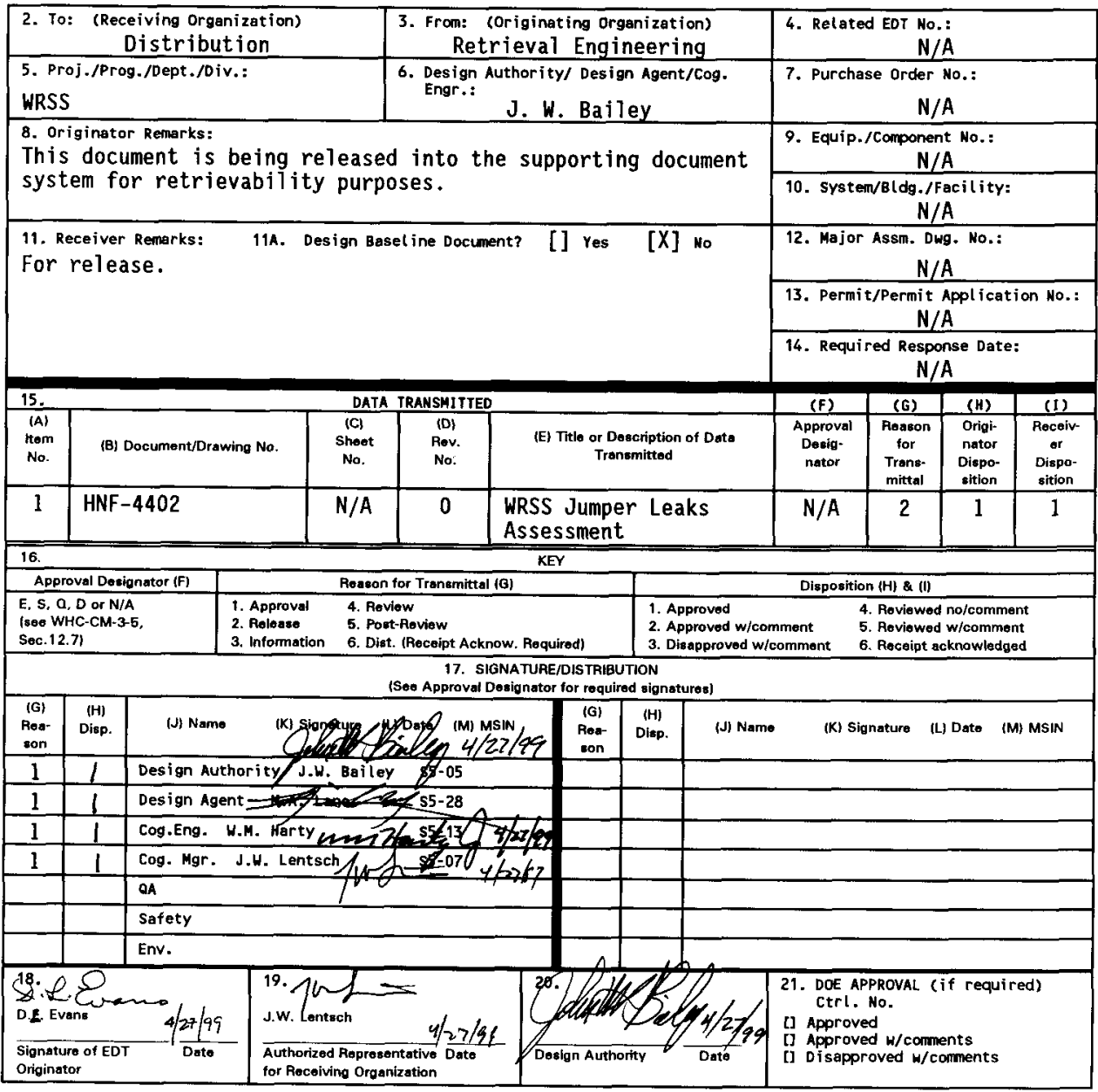

BD-7400-172-2 (05/96) GEF097 
HNF-4402, Rev. 0

\title{
WRSS Jumper Leak Assessment
}

\author{
J. W. Bailey
}

Lockheed Martin Hanford, Corp., Richland, WA 99352

U.S. Department of Energy Contract DE-AC06-96RL13200
EDT/ECN: EDT-610545
Org Code: 74B50
UC: 2070
B\&R Code: EW 3120074
CACN/COA: $101982 / E F O O$
Total Pages: 19

Key Words: Waste Retrieval Sluicing System, WRSS, Retrieval Project, Assessment, Jumper Leak, Lessons learned.

Abstract: N/A

TRADEMARK DISCLAIMER. Reference herein to any specific commercial product, process, or service by trade name, trademark, manufacturer, or otherwise, does not necessarily constitute or imply its endorsement, recommendation, or favoring by the United States Government or any agency thereof or its contractors or subcontractors.

Printed in the United States of America. Ta obtain copies of this document, contact: Document Control Services, P.O. Box 950, Mailstop H6-08, Richland WA 99352, Phone (509) 372-2420;
Fax (509) 376-4989.
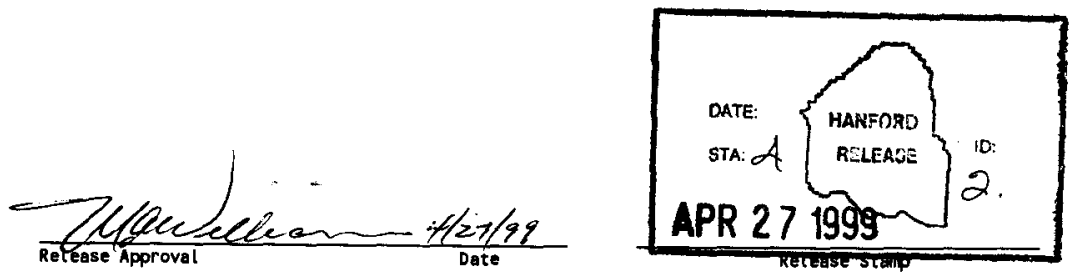

\section{Approved for Public Release}




\section{WASTE RETRIEVAL SLUICING SYSTEM (WRSS) JUMPER LEAK ASSESSMENT AND \\ LESSONS LEARNED DOCUMENT}

Prepared by Fluor Daniel Northwest, Inc. (FDNW)

For Lockheed Martin Hanford Corporation (LMHC)

M.A. Prybbylski and D.L. Evans, Principal Authors 


\section{TABLE OF CONTENTS}

$\begin{array}{lll}\text { Section Title } & \text { Page }\end{array}$

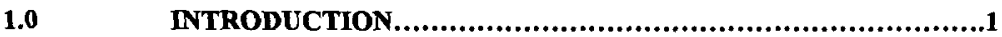

1.1 Problem Statement......................................................1

1.2 Background...............................................................2

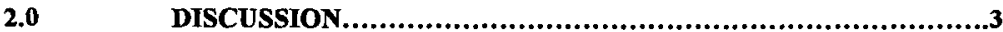

2.1 Jumper H-2-818502, "Pump Pit AY-02A-U3-U8-B”

(Waste Transfer Routing Jumper)....................................3

2.2 Jumper H-2-818516 "Sluice Pit C-06C-8-B"

(296-C-006 Process Building Drain Jumper)........................5

2.3 Jumper H-2-818515 "Sluice Pit C-06C-6-A"

(Sluicer Supply Jumper)................................................7

CORRECTIVE ACTIONS.........................................

3.1 Jumper H-2-818502, "Pump Pit AY-02A-U3-U8-B"

(Waste Transfer Routing Jumper)...................................10

3.2 Jumper H-2-818516 "Sluice Pit C-06C-8-B"

(296-C-006 Process Building Drain Jumper)........................10

3.3 Jumper H-2-818515 "Sluice Pit C-06C-6-A"

(Sluicer Supply Jumper).............................................11

CONCLUSION........................................................

4.1 Jumper H-2-818502, "Pump Pit AY-02A-U3-U8-B"

(Waste Transfer Routing Jumper) ...............................12

4.2 Jumper H-2-818516 "Sluice Pit C-06C-8-B"

(296-C-006 Process Building Drain Jumper)........................12

4.3 Jumper H-2-818515 "Sluice Pit C-06C-6-A"

(Sluicer Supply Jumper).........................................12

LESSONS LEARNED...........................................

6.0 REFERENCES....................................................

\section{FIGURES}

Figure $1 \quad$ 241-AY-02A Pump Pit..............................................4

Figure $2 \quad$ 241-C-06C Sluice Pit...................................................6 


\section{WRSS JUMPER LEAKS - ASSESSMENT}

\subsection{INTRODUCTION}

\subsection{Problem Statement}

The purpose of this assessment is:

1. to assemble and document the facts associated with three recently installed jumpers which have leaked either during actual process operation or during post installation testing;

2. to describe the corrective actions taken and to identify any process improvements which need to be implemented in the Hanford jumper design and installation activities; and

3. to document WRSS jumper leak lessons learned for use by future projects and other jumper design, fabrication, and installation activities.

The three jumpers described in this assessment are as follows:

Case \#1: Jumper H-2-818502 "Pump Pit AY-02A-U3-U8-B" (Waste Transfer Routing Jumper [Used for non-WRSS transfers]). In August of 1997, during a routine waste transfer from Tank 241-AY-101 to Tank 241-AW-102, waste was pumped through Pit 241-AY-02A "Pump Pit" via jumper AY-02A-U3-U8-B. The fluid level in Tank 241-AY-102 was found to be increasing, indicating a valve leak in the jumper.

Case \#2: Jumper H-2-818516 "Sluice Pit C-06C-8-B" (296-C-006 Process Building Drain Jumper). In August of 1998, while performing an Operating Test Procedure (OTP) of the High Efficiency Metal Filter, HMF-1361's, back flushing system, flush water was detected on the floor of Pit 241-C-06C "Sluice Pit". Leakage was subsequently observed around Nozzle B of the jumper.

Case \#3: Jumper H-2-818515 "Sluice Pit C-06C-6-A" (Sluicer Supply Jumper). During a sluicing campaign conducted on December 16,1998 , approximately 10 minutes after attaining system design flows, the leak detector in Pit 241-C-06C "Sluice Pit" alarmed. Subsequently, a leak was observed in the Sluice Pit around Nozzle 6 of the jumper. 


\subsection{Background}

The purpose of the Waste Retrieval Sluicing System (WRSS), provided by Project $\mathrm{W}-320$, is to transfer the high heat waste from the single-shell Tank 241-C-106 (Tank 6C) to the double-shell Tank 241-AY-102 (Tank 2AY). Supernate from Tank $2 \mathrm{AY}$ is used to mobilize the waste in Tank $6 \mathrm{C}$ by sluicing. The resulting slurry is returned to Tank $2 \mathrm{AY}$ where the solids are allowed to settle. To accomplish supernate and slurry flows, the following pumps and piping systems were installed. (Note, a complete description of the supporting systems and hardware necessary for sluicing is not included.)

Slurry transfers from Tank $6 \mathrm{C}$ to Tank $2 \mathrm{AY}$ are accomplished using the immersible Slurry Pump P-1361, in Tank 6C, operating in series with the Slurry Booster Pump P-1362 (a vertical in-line centrifugal pump), located in Pit 241-C06A. The slurry is pumped through a new 4-inch pipe-in-pipe transfer line (4"SL100). Jumper C-06A-9-A provides the connection between the 4"SL-100 line and the Slurry Booster Pump. Jumper AY-02A-U11-A-(C) provides the connection between the 4"SL-100 line and the Slurry Distributor D-0621, located in Pit 241AY-02A.

Supernate transfers from Tank $2 \mathrm{AY}$ to Tank $6 \mathrm{C}$ are accomplished by using the immersible Sluice Pump P-0621, in Tank 2AY, operating in series with the Sluice Booster Pump P-0622 (a vertical in-line centrifugal pump), located in Pit 241AY-02E. The supernate is pumped through a new 4-inch pipe-in-pipe transfer line (4"SN-200). Jumper AY-02E-U2-A-(B) provides the connection between the 4 "SN-200 line and the Sluice Booster Pump. Jumper C-06C-6-A provides the connection between the $4^{\prime \prime}$ SN-200 line and the Sluicer S-1361 located in Pit 241C-06C.

Process Building 241-C-91, located on grade next to Tank 6C, contains equipment and support systems used to condition, filter and exhaust air from the tank. The building includes an equipment and floor drain system. Drain line 3"DR-301 is from the building's floor drain and 3"DR-302 is from the High Efficiency Metal Filter HMF-1361's drain. The two lines combine together and enter Pit 241-C-06C through Nozzle 8. Jumper C-06C-8-B provides the connection between Nozzle 8 and the Sluicer S-1361 located in Tank 6C's Pit 241-C-06C. The Sluicer includes a drop leg, which routes the drain flow into Tank 6C.

Waste transfers are currently routed through AY-Farm, using the existing Jumper AY-02A-U3-U8-B, located in Pit 241-AY-02A. A replacement jumper was fabricated to maintain this transfer capability after installation of the Slurry Distributor. The jumper connects the existing 2"-SL-503 and 2"-SL-504 lines via nozzles U-3 and U-8, respectively, and provides a third branch to Tank $2 \mathrm{AY}$ through floor Nozzle B. Installation of the Slurry Distributor required relocation of Nozzle B. 


\subsection{DISCUSSION}

This section describes the operations and activities leading to the detection of the leaking jumpers. Data was collected through interviews with personnel from engineering, design, construction, and operations. Design media was examined; fabrication, construction and installation processes were discussed; and the preoperational testing performed was reviewed. Videotapes and photos produced during installation, testing and operation were also reviewed.

\subsection{Jumper H-2-818502, "Pump Pit AY-02A-U3-U8-B" (Waste Transfer Routing Jumper)}

Jumper AY-02A-U3-U8-B was fabricated and installed to maintain current waste transfer routings, through AY-Farm, impacted by the installation of the Slurry Distributor in Pit 241-AY-02A. This jumper connects the existing 2"-SL-503 and 2"-SL-504 lines via nozzles U-3 and U-8, respectively, and provides a third branch to Tank $2 A Y$ through floor nozzle B, see Figure 1. Installation of the Slurry Distributor relocated Nozzle B. The desired routing is selected by manipulating a 2 -inch, 3-way ball valve in the jumper.

The jumper has three legs, three end connections, one 3-way ball valve, and no instruments. Prior to the jumper fabrication, nozzle locations, to within $\pm 1 / 64$ in., were obtained by a field survey crew for use on the jumper design drawings. The jumper was fabricated in accordance with Hanford Standard HS-BS-0084, Rev. B. Test records show the jumper passed a hydrotest with the ball valve open.

The jumper was installed in the pit and the pit cover blocks replaced. The jumper was then turned over to operations to support waste transfers through AY-Farm; ref. HNF-SD-W320-ABU-003. 


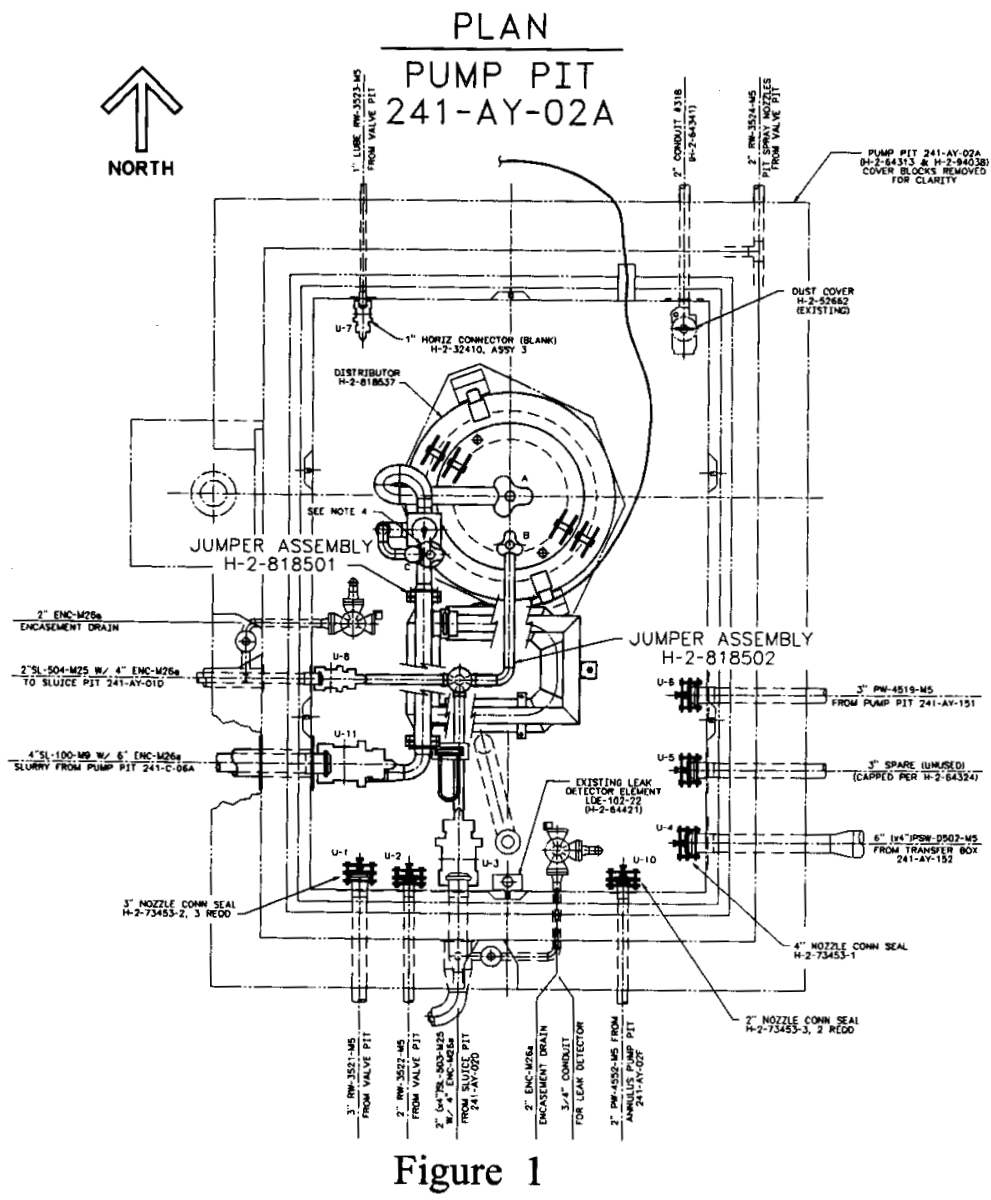

In August of 1997, a routine waste transfer from Tank 241-AY-101 to Tank 241AW-102 via Jumper AY-02A-U3-U8-B was conducted. During the transfer, it was observed that the fluid level in Tank $2 \mathrm{AY}$ increased approximately $1 / 2$-inch over the course of a day. (This correlates to a valve leak rate of approximately 1 gallon-per-minute, gpm.) Over a multiple day campaign the fluid level in Tank $2 \mathrm{AY}$ increased approximately 3 -inches. In-tank videotapes revealed that the 
waste was coming into the tank through the drop leg connected to Nozzle B, i.e., via the leg of the jumper that should have been closed off by the ball valve.

During the transfer, operators rotated the tee handle of the ball valve to various settings in an attempt to get the valve to seat properly (close).

\subsection{Jumper H-2-818516 “Sluice Pit C-06C-8-B” (296-C-006 Process Building Drain Jumper)}

Pit 241-C-06C "Sluice Pit", contains the Sluicer S-1361, which is installed in an existing 12-inch riser (R-3), and Jumpers C-06C-8-B and C-06C-6-A; see Figure 2. Jumper $\mathrm{C}-06 \mathrm{C}-8-\mathrm{B}$, drain jumper, provides the connection between the new Process Building drain line and Tank 6C, via wall Nozzle 8 and sluicer Nozzle B.

The drain jumper has two end connections, and no valves or instruments. There is one horizontal connector (8) and one vertical connector (B). The jumper was fabricated in accordance with Hanford Standard HS-BS-0084, Rev. B, and passed the required hydrotest.

The radiation levels, in the Sluice Pit, are between 15 and 30 Rad and no manned entry is allowed. Installation of jumpers, new nozzle assemblies, and project ancillary equipment were done remotely through the use of mirrors, video cameras, cranes, and special tools. After component installation a field survey crew, because of lack of pit entry, was not able to determine exact nozzle locations, i.e. $\pm 1 / 64$ in.

The drain jumper installation sequence was as follows: (Note: The nozzle and jumper installation for the Jumper C-06C-6-A “Sluicer Supply Jumper", described in paragraph 2.3, and the drain jumper are similar. The common elements of the installation will be detailed below and not repeated).

- New holes were core drilled in the pit walls to provide for the installation of the 4"SN-200 process line (Nozzle 6), the 3"DR-302 drain line (Nozzle 8), and their associated encasement drain lines.

- The sluicer was staged into the pit and installed in Riser R-3 (Nozzles A and $B$ are part of the shuicer assembly). As part of the sluicer preparation for installation counterweights were added as required to cause the assembly to hang vertically. 


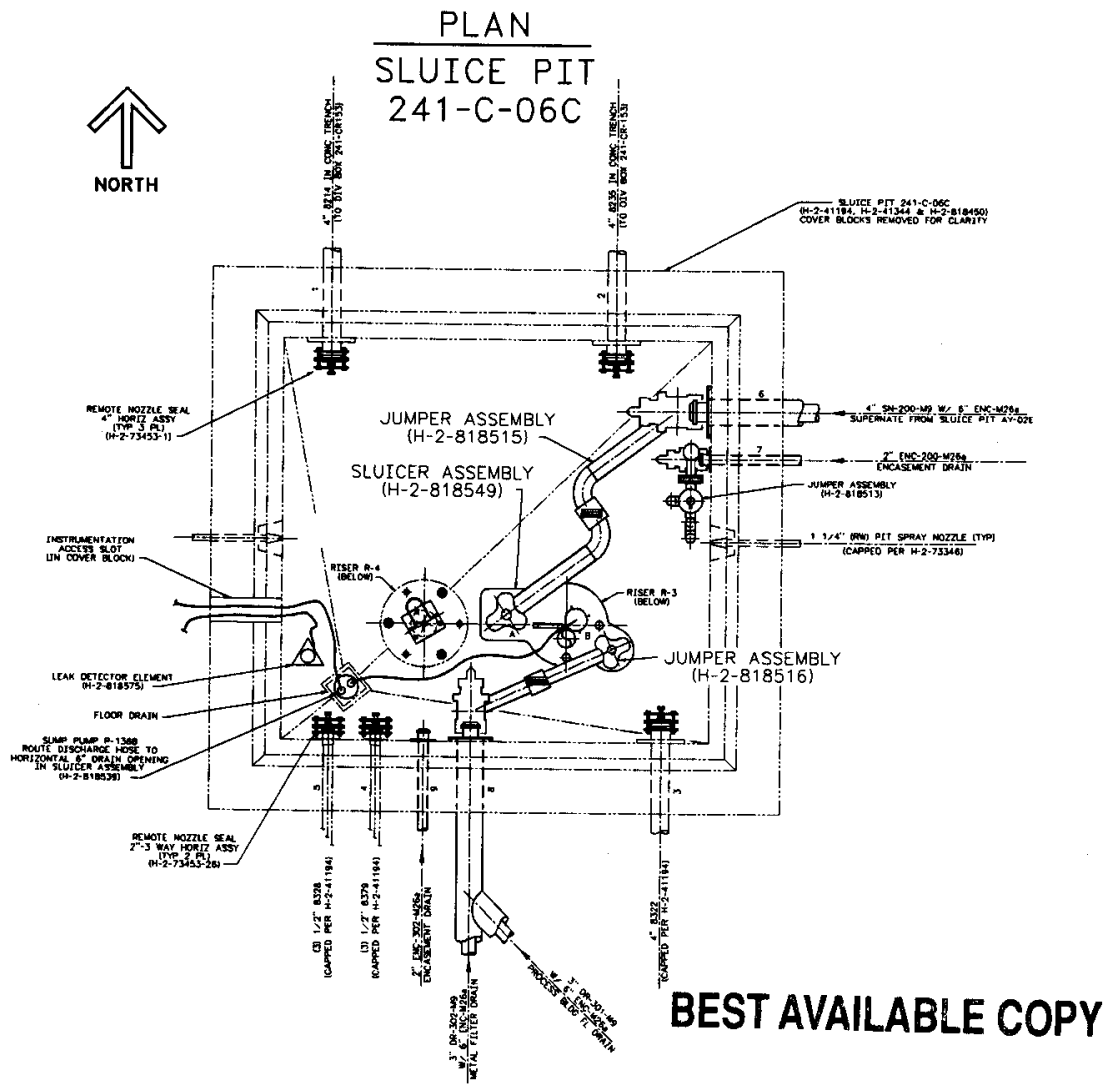

Figure 2

- Each nozzle includes a standard kickoff plate and short sections of both the process/drain pipe and pipe encasement. Since no manned entry was allowed, special tools and rigging were used to lower the nozzles into the pit and pull them through the newly core drilled holes from the outside. The assemblies were loosely held in place by three centering guide fins, while the jumpers were installed.

- The drain jumper was lowered into the pit and connected to the sluicer at Nozzle B and the drain line at wall Nozzle 8. The jumper's end connectors 
were mechanically tightened geometrically pinning the jumper in place. The jumper became a "jig" establishing the exact placement of Nozzle 8 and the nozzle was then grouted. Construction forces had difficulty setting the drain jumper in place. Videotape reveals that as one connector was tightened the other connector would displace off of its nozzle, and vice-versa. The jumper was taken off and put on several times, to try and obtain a fit-up, and finally connected

- After installation of the nozzles and completion of other pit work, the cover blocks were lowered into place. As the last cover block was set in place, it was observed that the sluicer's rotating shaft did not align properly within its associated cover block port. Upon further inspection, it was noticed that the sluicer was leaning slightly to the east, i.e. the assembly was not true, vertically.

- A video camera was lowered through a cover block camera port and used to inspect the sluicer installation. The sluicer's added counterweights were observed to be sitting on top of an existing pit floor dowel pin. This interference did not allow the sluicer to seat squarely on riser R-3's mounting flange. The west side of the sluicer base appeared to be elevated approximately 1 " causing the top section of the rotating shaft to lean approximately 4 " to the east. Also, the drain jumper's connector at Nozzle B was observed to be improperly seated.

- The cover blocks were removed, the jumpers loosened, the sluicer lifted (taking the weight off the dowel pin) and the dowel pin cut with a remotely operated portable band saw. The sluicer was then lowered and the jumpers retightened. The drain jumper was lifted and reset prior to tightening. After completing the installation of the jumpers, the drain jumper end connections were examined using the video camera and determined to be properly madeup.

Several months later an Operational Test Procedure, OTP, was performed on the High Efficiency Metal Filter, HMF-1361. Part of the OTP requires back flushing HMF-1361 using water. The water flush was followed by an alarm from the sluice pit leak detector. A video camera was installed in the sluice pit and water was observed leaking from the drain jumper's end connection at Nozzle B.

\subsection{Jumper H-2-818515 “Sluice Pit C-06C-6-A" (Sluicer Supply Jumper)}

Jumper C-06C-6-A, sluicer supply jumper, is located in the 241-C-06C "Sluice Pit" and provides the connecting piping between the new supernate line, 4" SN200, (at Nozzle 6), and the sluicer (at Nozzle A).

The supply jumper has two end connections and no valves or instruments. There is one horizontal connector (6) and one vertical connector (A). The jumper was fabricated in accordance with Hanford Standard HS-BS-0084, Rev. B, and passed the required hydrotest. 
The radiation levels in the pit are between 15 and $30 \mathrm{Rad}$, and all equipment was installed remotely. No field survey determination of the installed equipment location was possible.

The supply jumper installation sequence was similar to that used for the drain jumper, described in paragraph 2.2, and was as follows; (see paragraph 2.2 for additional sequence details).

- After the sluicer was installed, Nozzle 6 was loosely held in place, by centering guide fins, while the supply jumper was set in position.

- The jumper's end connections were tightened and the jumper was used as a jig to hold Nozzle 6 in place while the nozzle was grouted. Unlike the drain jumper, construction forces had no difficulty setting the supply jumper in place. Construction forces noted that the electric hammer did not seem to ratchet "kick" in a normal manner when the final torque was applied to the Nozzle 6 connector. However; it was judged that a "tight" fit-up was achieved.

- The jumper's end connections were subsequently loosened to support the removal of the dowel pin. The sluicer was set squarely on the riser flange face and the jumper end connections re-tightened. The end connections were then examined using the video camera and determined to be properly made-up.

- The cover blocks were set in place and installation of the sluicer completed.

Subsequent replacement of the leaking drain jumper began with the removal of sluicer drive assembly. Removing the drive assembly requires the sluicer's rotating shaft and rack actuating rod be secured using a custom machined slotted screw. The drive assembly includes a brass bushing which has a tight running fit with the rotating shaft.

During the initial attempt at removing the drive assembly, the machined screw from the spare sluicer was used. This caused interference between the rotating shaft and the bushing, which lifted the rotating shaft assembly.

The rotating shaft assembly is free to move up and down between stops within the sluicer assembly. If the lower stop is engaged, the rotating shaft will then lift the sluicer, including the attached jumpers. Construction forces observed the movement of the rotating shaft and terminated the lift before the lower stop was reached. The reading on the crane's dynamometer increased, indicating more than the drive assembly was being lifted; however, it did not display the weight of the entire sluicer plus attached jumpers. The custom machined screw for the installed sluicer was located and inserted into the rotating shaft. The drive assembly was then removed without further incident.

After replacement of the drain jumper, both jumpers were leak tested. The supply jumper was tested with a water flush, using a flow rate of approximately $120 \mathrm{gpm}$ 
and a pressure of $15 \mathrm{psi}$, to ensure that the nozzle connections were tight. The jumper passed the test. After testing, the cover blocks and sluicer drive assembly were installed.

The first sluicing campaign was conducted November 18, 1998. The campaign lasted for 2 hours and ran at design flows and pressures. No leaks were detected in any of the pits.

A second campaign (process test) was run on December 16, 1998. Data entries in the Operator logbook indicate that during this test, the Sluice Pump P-0621 was started and stopped several times. After four start/stop cycles, the Sluice Pump was started and flow was established in the supernate line through the sluicer nozzle. The Sluice Booster Pump P-0622 was then energized and ramped up to $100 \%$ speed. Approximately 10 minutes after attaining system flows, the leak detector in Pit 241-C-06C "Sluice Pit" alarmed and the test was terminated. A leak was later observed, using the camera, at the supply jumper's Nozzle 6 connection, during a water flush.

Informal communication with operators, supporting calculations, and videotapes all indicate that it takes a little over ten minutes for the 4"SN-200 line to drain. During two of the cycles, the Sluice Pump was off for less than ten minutes. When the pump was re-started after these cycles, an air column was trapped in the piping. In-tank video shows a mixed fluid flow, air and water, during these two events. The sluicer nozzle appears to make a transition from solid stream flow, to spray flow and back to solid flow. A calculation was done assuming the sluicer nozzle made a pressure transition from zero to $140 \mathrm{psi}$ (the pressure drop across the nozzle at design flow) faster than the critical time (the time for a round trip of a pressure wave in the pipe system) of the pipeline; see Reference 4a. The calculation found the resulting water hammer was $280 \mathrm{psi}$, which is below the design pressure (360 psi) of the pipe system.

A new jumper was fabricated to replace the leaking jumper. During removal of the existing jumper, construction forces noted that the electric hammer did not seem to ratchet "kick" in a normal manner when the break-away torque was applied to the Nozzle 6 connector, i.e. it was judged that the connection was not "tight". 


\subsection{CORRECTIVE ACTIONS}

This section describes what is believed to be the problem, and the corrective actions taken or planned for each case.

\subsection{Jumper H-2-818502 "Pump Pit AY-02A-U3-U8-B" (Valved Routing Jumper)}

From an ALARA standpoint, the routing jumper was too radioactively hot to repair or to conduct a teardown to determine the cause of failure. It was wrapped and placed in a burial box for disposal. It was not determined if the valve had an internal seal failure, the valve stem and Tee handle were misaligned, or another fault caused the valve to leak. A new jumper was fabricated, tested in the shop to modified testing criteria, and installed.

The modified testing criteria for the new jumper assembly included positioning the valve such that each branch of the jumper was hydrotested separately verifying that the valve successfully blocked pressure (flow) to the valved out leg. The new jumper valve successfully held the test pressure in each of these pressure tests.

After the new jumper 02A-U3-U8-B was installed, a test with water was performed. The jumper connections passed, without observable leakage.

FDNW engineering issued a guidance notice directing implementation of similar testing for jumpers designed and fabricated by FDNW.

\subsection{Jumper H-2-818516 "Sluice Pit C-06C-8-B" (296-C-006 Process Building Drain Jumper)}

Videotape documentation of the drain jumper installation confirmed the difficulty construction forces had with the fit-up.

The video did not reveal the true cause of the problem. It was speculated that the wall nozzle was skewed when installed, because the jumper was used as a jig connecting it to the tilted sluicer. After the sluicer was seated correctly, a proper alignment may have been difficult to achieve. It was also speculated that one of the jaws was not grabbing Nozzle B, although that was never confirmed. After completing the jumper installation, a video inspection did indicate a proper fit-up.

The decision was made to replace the leaking jumper with a modified jumper. The new jumper included a short length of stainless steel braided flexible hose, which provided enough flexibility in the jumper to accommodate the postulated 
wall nozzle misalignment. The jumper installation went without trouble, and it was re-tested and passed.

\subsection{Jumper H-2-818515 “Sluice Pit C-06C-6-A” (Sluicer Supply Jumper)}

The supply jumper passed a post-installation flush test with water, and was used without incident during the first sluicing campaign in November of 1998 . The system was designed to operate using the Sluice Pump in series with the Sluice Booster Pump. The normal sequence of this operation is to energize the Sluice Pump and establish supernate flow through the sluicer nozzle. With only the Sluice Pump running, the system flow rate is approximately $170 \mathrm{gpm}$. Once the system is primed, the Sluice Booster Pump is brought up to speed to deliver the system design flow of $350 \mathrm{gpm}$.

The process test, conducted on December 16, was run to obtain data on ventilation stack emissions. The Sluice Pump was started and stopped several times. After 4 cycles, the Sluice Pump was started, the line filled, and Sluice Booster Pump started. After system design flows were obtained the Sluice Booster Pump was ramped up to deliver approximately $405 \mathrm{gpm}$. The procedure called for $450 \mathrm{gpm}$, but that was beyond the capability of the sluice pumping system. The test was shut down when the Sluice Pit leak detection alarm sounded.

After the process test, a water flush of the supernate line was conducted with a camera installed in the Sluice Pit. During the flush a leak was observed at wall Nozzle 6. Videotape data did not reveal the cause and on close examination the connector appeared to have proper fit-up. The supply jumper was too radioactively hot to repair or to conduct a teardown to determine the cause of failure. It was wrapped and placed in a burial box for disposal. During removal, the end connector and wall nozzle were examined using the video camera. No apparent deficiencies were observed

The decision was made to replace the leaking jumper with a modified jumper. The new jumper included a short segment of flexible hydraulic hose. The hose used had a high pressure rating and lacked internal corrugations of a bellows, which could hold up solids and expose the design to higher erosion wear. After installation, the new jumper was leak tested. The leak test was performed using water at system design flow rates (>350 $\mathrm{gpm})$. 


\subsection{CONCLUSION}

Conclusion concerning the causes of the leaking jumpers follows:

\subsection{Jumper H-2-818502 "Pump Pit AY-02A-U3-U8-B” (Waste Transfer Routing Jumper [Used for non-WRSS transfers])}

In August of 1997, during a routine waste transfer from Tank 241-AY-101 to Tank 241-AW-102, the valve in jumper AY-02A-U3-U8-B leaked. The jumper was radioactively hot and could not be examined.

It was not determined if the valve had an internal seal failure, the valve stem and Tee handle were misaligned, or another fault caused the valve to leak.

\subsection{Jumper H-2-818516 “Sluice Pit C-06C-8-B” (296-C-006 Process Building Drain Jumper).}

In August of 1998, while performing an OTP on the HMF-1361, flush water was detected on the floor of the Sluice Pit. Leakage was subsequently observed around Nozzle B of the jumper.

Although all video camera imagery indicated a sound connection during instaliation, the jumper appears to not have been properly seated on sluicer Nozzle B.

\subsection{Jumper H-2-818515 "Sluice Pit C-06C-6-A" (Sluicer Supply Jumper).}

While sluicing, in December of 1998, the leak developed in the Sluice Pit at Nozzle 6 . Nozzle 6 was grouted in place using the supply jumper as a "jig". At this time the jumper was rigidly fixed to the sluicer while the sluicer was not set squarely on its mounting flange. The sluicer placement was corrected and the jumper end connections re-tightened. After installation the supply jumper passed a pre-operational leak check and no leakage was detected during the initial sluicing campaign conducted in November.

The jumper was radioactively hot and, during removal, could only be examined from a distance or by video camera. Neither of these methods observed an obvious fault. Construction forces did note that the connection of Nozzle 6 appeared not fully torqued when the jumper was removed. While sluicing, the Sluice Pump was cycled causing a mixed flow rheology at the sluicer nozzle. Review of the in-tank video and the results of the water hammer calculation do not support an obvious over stressing of the pipe system. 
Without careful physical examination of the jumper the cause of the connection failure cannot be identified with certainty. However; the exact alignment between a jumper and its nozzles is considered of critical importance. Placing a loosely guided nozzle, using a jumper attached to a piece of equipment later repositioned, calls into question the soundness of the final fit-up. No single factor appears responsible for the leak. A combination of nozzle placement to the misalign sluicer and pressure cycling during operations may have lead to the leak. It is possible that the jumper misalignment during construction later loosened and leaked during operations at design flows and pressures. 


\subsection{LESSONS LEARNED}

This section describes lessons learned from project W-320 jumper leaks described in this document.

- Jumpers which contain valves should be tested to assure that all the valves internal seals are sound. The valve should be manipulated to test all jumper branches to ensure that it blocks flow or limits leakage to the valved-out section(s), to the extent required by the specific application involved.

- Use of semi-rigid jumpers (jumpers with short pieces of stainless steel flexible hose or hydraulic hose) should be considered, where nozzle configurations (as-built data) cannot be verified, where high dose / difficult remote installation is required, or where difficult tolerance buildup problems exist. The use of flexible jumpers presents other problems that need to be considered: 1) The installation gets complicated and may require two hooks to install the jumper and two hooks may require two cranes thereby increasing the dome load on waste tanks; 2) The analysis needs to consider the end loads imposed by the jumper; 3 ) The jumper may require additional support structure to hold it rigid while it is being installed; 4) Hose materials potentially have a lower resistance to radiation, and erosion; and 5) Flexible section including corrugations are hard to flush out and become sources for contamination traps.

- If it is technically and financially practical to decontaminate and break down failed jumpers, they should be examined to determine the problem's root cause.

- When "leaky" jumpers are removed, pit nozzles should be inspected to see if they contain faults.

- When as-built information is not available use photogrammetry where feasible to obtain nozzle locations.

- After installing wall nozzles mating jumpers should be connected and tested. The test should be conducted prior to installing the connecting piping (on the outside of the pit) to the nozzle stub that protrudes through the pit wall. This will lessen the amount of water used for the test and will identify leaks early in construction.

- In-place testing of jumpers should be performed at design conditions if possible. 
- Consideration should be given to providing some type of tell-tale indicator (i.e., paint a stripe) on the jumper nut threads so that remote observation of the location of the stripe would indicate that the connector has been properly engaged; this would be done as part of the jumper fabrication.

- During installation of jumpers, video camera inspection should be employed to observe the tightening of the jumper connectors to watch for thread engagement, hook engagement, and impact wrench ratcheting.

- During jumper fabrication, determine (measure) the proper torque to be applied to the connector nut to ensure the connector is properly made up. Subsequently, during installation, use the shop-measured torque values when tightening the nut.

- Consider the addition of a torque-limiting device on the impact wrenches. This measure would ensure that the connectors are tightened within the proper (specified) torque range.

- Caution should be observed during construction to ensure rigid jumpers are not cold sprung during installation.

- Jumper nozzle alignment should be reconfirmed following any repositioning of connecting equipment.

- All alignment problems associated with jumper installation should be thoroughly reviewed by the design agent.

- There are several projects that are in progress designing and fabricating jumpers. These lessons learned need to be communicated to these project/construction teams to ensure that they can take full benefit from them in planning their jumper design, fabrication and installation activities.

- Where feasibly, new wall nozzles should be installed in a manner that ensures the nozzle is plump and perpendicular with the pit wall, and that high accuracy as-built dimensions are taken from the installed nozzle, reference HWVP meeting minutes PUREX Connector Workshop 7F133-MM92-001 and Hanford Standard for Jumper Fabrication, HS-BS-0015. 


\subsection{REFERENCES}

1. Jumper Assembly Drawings:

$$
\begin{array}{ll}
- & \text { H-2-818501, "AY-02A-U11-A-(C)" } \\
- & \text { H-2-818502, "AY-02A-U3-U8-B" } \\
\text { H-2-818505, "C-06A-9-A" } & \text { H-2-818508, "C-06A-B-(A)" } \\
: \quad \text { H-2-818515, "C-06C-6-A" } \\
\quad \text { H-2-818516, "C-06C-8-B" }
\end{array}
$$

2. Conversation Notes:
a. W320-CN-001
b. W320-CN-002
c. W320-CN-003

3. Videos

4. Calculations

a. W-320-27-057 "Slurry Line Start-up Water Hammer 


\begin{tabular}{|c|c|c|c|c|c|}
\hline \multicolumn{6}{|c|}{ DISTRIBUTION SHEET } \\
\hline \multirow[b]{2}{*}{ Distribution } & \multirow{2}{*}{\multicolumn{3}{|c|}{$\begin{array}{l}\text { From } \\
\text { Retrieval Engineer }\end{array}$}} & \multicolumn{2}{|l|}{ Page 1 of 1} \\
\hline & & & & \multicolumn{2}{|l|}{ Date $04 /$} \\
\hline \multicolumn{4}{|c|}{ Project Title/Work Order } & \multicolumn{2}{|l|}{ EDT No. N/A } \\
\hline \multicolumn{4}{|c|}{ HNF-4402, Rev. 0, "WRSS Jumper Leak Assessment" } & \multicolumn{2}{|l|}{ ECN No. $N / A$} \\
\hline Name & MSIN & $\begin{array}{c}\text { Text } \\
\text { With } \\
\text { All } \\
\text { Attach. }\end{array}$ & Text Only & $\begin{array}{l}\text { Attach./ } \\
\text { Appendix } \\
\text { Only }\end{array}$ & $\begin{array}{l}\text { EDT/ECN } \\
\text { Only }\end{array}$ \\
\hline
\end{tabular}

\section{COGEMA}

J. R. Bellomy

Lockheed Martin Hanford Corp.

D. G. Baide

G. N. Hanson

W. M. Harty

Lockheed Mart in Services, Inc.

WRSS Files

Numatec Hanford Corporation

J. W. Bailey

J. W. Lentsch

Fluar Daniel Northwest

D. L. Evans

M. A. Lane

M. A. Przybylski

Project Files

\$5-05 $\quad X$

S5-05

55-07

S5-13

R1-29 X

S5-05

S5-07

S5-28

S5-28

A3-04

B4-57
$X$
$X$
$X$

$X$
$X$

$x$

$x$
$x$
$x$

$X$

$X$
$X$
$X$
$X$ 